\title{
Review: Rice momilactones, potential allelochemical for weeds suppression
}

\author{
AMY ESTIATI \\ Research Center for Biotechnology, Indonesian Institute of Sciences. Jl. Raya Bogor Km. 46 Cibinong, Bogor 16911, West Java, Indonesia. \\ Tel.: +62-8754587, Fax.: +62-21-8754588, email: nugroho_amy@yahoo.com
}

Manuscript received: 28 September 2018. Revision accepted: 16 January 2019.

\begin{abstract}
Estiati A. 2019. Rice momilactones, potential allelochemical for weeds suppression. Asian J Agric 3: 6-15. Weeds are one of the biological constraints declining the productivity and quality of rice. Among weeds, barnyardgrass is reported as the most destructive weed species. Synthetic herbicides are the preferred method to control weeds. However, the excessive and continuous use of synthetic herbicides can have a negative impact on the environment, health and even the emergence of herbicide-tolerant weeds. Therefore, another alternative to overcome weed problems has concerned scientists. Rice plants have been proven to be able to suppress the growth of weeds nearby by secreting secondary metabolites called allelochemicals. In this article, the achievements of research on rice allelochemicals at laboratory level will be reported. Among rice allelochemicals, momilactones are potential growth inhibitors. The biosynthetic pathway of momilactones and their corresponding genes have been extensively investigated in rice. OsCPS4, OsKSL4, CYP99A2, CYP99A3 and OSMAS are genes that co-regulated in momilactones biosynthetic pathway and production, and they form a gene cluster which is located on chromosome 4. Reverse genetic approach by inserting genes knock-out of OsCPS4 and OsKSL4 into two rice cultivars from Japonica subspecies showed that insertional mutant lines harboring cps 4 or ksl 4 exhibited a significant loss in inhibition potential due to the lack of momilactones production.
\end{abstract}

Keywords: Allelochemicals, growth inhibitor, momilactones, rice, weeds

\section{INTRODUCTION}

Rice (Oryza sativa L.) is a staple food in many regions around the world, especially in Asia. It globally provides approximately $20 \%$ of the caloric intake to more than $50 \%$ of the world's population (Khanh et al. 2013; Siddique and Ismail 2013; Amb and Ahluwalia 2016). With an increasing human population, rice production must increase to fulfill food security. However, cultivated rice is faced with problems that come from biotic and abiotic stresses, which lead to a decrease in productivity and quality. Weeds, insect pests, diseases, and abiotic stresses are major threats to rice production and climatic changes can worsen the situation (Farooq et al. 2013). Weed infestations are reported as the main biological constraint in reducing rice production. The loss of yield due to weed infestations is greater than the combined yield losses caused by insect pests and diseases (Asaduzzaman et al. 2010; Khang et al. 2016).

In paddy fields, cultivated rice and weeds always grow together although both plants compete for the same needs i.e., water, nutrient, light, space, and requirements for photosynthesis (Khanh et al. 2013). Weeds have competitive ability over cultivated rice since weeds grow taller and faster. Therefore, the presence of interfering weeds is a persistent problem for rice (He et al. 2012).

Worldwide, more than 1000 weeds species have been reported in paddy fields (Khanh et al. 2013). However, 12 of them are the important weeds species in Asia, i.e., Cyperus difformis L. (small flower umbrella), Cyperus iria's L. (rice flatsedge and umbrella sedge), Echinochloa crus-galli (L.) Beauv (barnyardgrass), Echinochloa colona (L.) Link. (jungle rice), Eclipta prostrata (L.) L. (false daisy), Fimbristylis miliacea (L.) Vahl (lesser fimbristylis), Ischaemum rugosum Salisb. (wrinkle duck beak), Leptochloa chinensis (L.) Nees (chinese sprangletop), Ludwigia hyssopifolia, Schoenoplectus juncoides, Sphenoclea zeylanica Gaertn (Gosseweed), Oryza sativa L. (weedy rice) (Rice Knowledge Bank). Among 12 weeds, barnyardgrass is reported as the most destructive weed and one of the most serious herbicide-resistant weeds (Tanveer et al. 2012; Zeinali et al. 2013). The presence of barnyardgrass together with rice plants in paddy fields can reduce rice production. When the ratio of rice plants to barnyardgrass in paddy fields is 10:1, this weed can reduce rice biomass and yields by $75 \%$ and $50 \%$, respectively (He et al. 2012; Gealy et al. 2013; Yang et al. 2013).

Synthetic herbicides are believed to control weeds problems effectively, prevent crop yield loss and reduce labor in weeding. However, the use of synthetic herbicides can raise other problems such as high cost for crop production, the use of non-renewable energy resources, the excessive and overuse of herbicides may lead to the evolution of resistance in some paddy weeds to herbicides. Moreover, the negative effects on the environment and human health cannot be neglected (Fereira and Reindhart 2010; Bhadoria 2011; Mohammadi 2013). Thus, an alternative method to control weeds problem by minimizing the use of synthetic herbicide should be considered. 
Allelopathy is reported as a self-defense mechanism of rice plants against weeds by suppressing weed growth. Although, in the rice fields, the weed-suppressive effect is more complex. It is a combination of competition for resources and the release of allelochemicals from rice varieties (Kato-Noguchi and Ino 2001; Kong et al. 2008). Laboratory bioassay is one of the appropriate methods for conducting preliminary studies on allelopathy because it is conducted under a controlled environment that can distinguish allelopathy effect from other competitive interference (Kato-Noguchi and Ino 2001). This paper reviews the published literature focused on allelopathy potential in rice plants and determines the allelopathy compounds that play an important role in inhibiting weed growth at laboratory level.

\section{ALLELOPATHY, AN ALTERNATIVE TO SYNTHETIC BIOHERBICIDES}

Allelopathy is defined as any direct or indirect harmful or beneficial effects on germination, growth, and development of one plant on another through the production of chemical compounds called allelochemicals that release into the environment (de Bertoldi et al. 2009; Bhadoria 2011; Bravo et al. 2013; Khanh et al. 2013). Although allelopathy has either a negative or positive effect, however many ecologists tend to interpret that allelopathy has only a negative effect from one plant to the surrounding plants which is considered as interfering plants by inhibiting their growth. These mechanisms occur to defend plants themselves (Bhadoria 2011; Bravo et al. 2013). The negative impacts of allelochemicals are harmful to the receiver plants but give a benefit to the donor plants (Bravo et al. 2013).

Many crops, including rice, have been reported to possess allelopathy properties (Dilday et al. 1989; Bhadoria 2011; Bravo et al. 2013; Amb and Ahluwalia 2016). To select rice accessions with strong allelopathic, International Rice Research Institute in the Philippines has developed well-designed bioassays at laboratory level under controlled environments called relay-seedling assay. This method eliminated the effect of resource competition between rice and test plants, thus the data obtained will represent only plant allelopathy (Kato-Noguchi 2004; Kato-Noguchi and Peters 2013). Relay-seedling assay has been routinely used in screening of hundreds of rice accessions and resulting in several rice accessions with strong allelopathic potential (Jensen et al. 2001; Olofsdotter et al. 2002).

By using relay-seedling assay, Olofsdotter et al. (2002) evaluated the effect of allelopathy from 50 rice cultivars on root elongation of barnyardgrass (one of the most destructive weed species) as a test plant. Thirty sterilized rice seeds were grown in Petri dish in two parallel rows and covered by Perlite. The distilled water flowed into Petri dish to maintain the moisture of Perlite. The Petri dishes were placed under 1300-3000 lx light density, with a photoperiod of $12 \mathrm{~h}$ and temperature between $29-33^{\circ} \mathrm{C}$. On day 7, 20 barnyardgrass seeds as test plant were sown in between two rows of 7 -day-old rice seedlings in Petri dish. The root growth of barnyardgrass was measured at 17 days after incubation. The results exhibited that the roots growth of test plant were inhibited by 50 rice cultivars used with different reduction rate between $55 \%-81 \%$. Data showed that 50 rice cultivars have different abilities in suppressing root growth of barnyardgrass, thus the activity of allelopathy is cultivars-specific. Based on this data, the 50 rice cultivars can be categorized as allelopathic cultivars and non-allelopathic cultivars (Olofsdotter et al. 2002). Microscope studies showed that secondary root growth of barnyardgrass was inhibited with the presence of allelopathic rice seedlings, meanwhile, no significant reductions were exhibited when grown together with nonallelopathic rice (Figure 1).
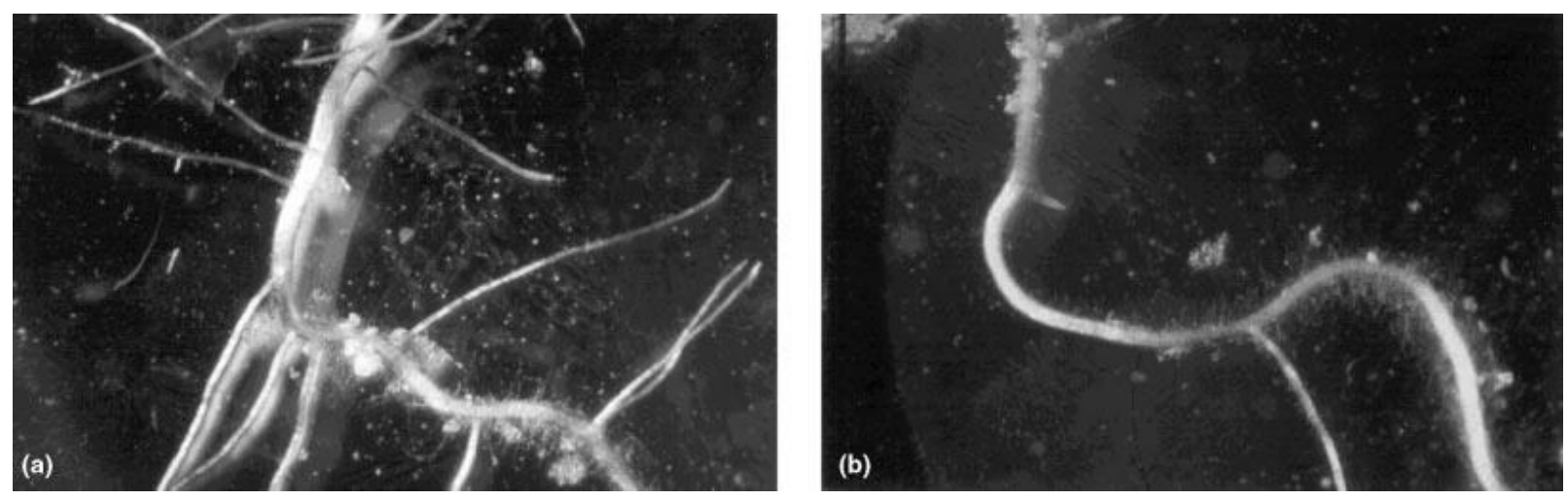

Figure 1. The secondary root growth of barnyardgrass when they grow together with rice seedlings of (a) non-allelopathic rice (Aus 196) and (b) allelopathic rice (IR64) in Petri dish. Secondary root growth of barnyardgrass was inhibited by the presence of allelopathic rice, IR64 (Source: Olofsdotter et al. 2002). 
Since cultivated rice has defense mechanisms toward weed species through the production of allelochemicals, these allelopathic compounds are considered plantproduced herbicides (Colquhoun 2006). And, since rice allelopathy is environmentally friendly and secreted from rice itself, utilizing allelopathy to suppress weeds growth surrounding cultivated rice as a promising approach for biological control of weeds in sustainable agriculture practice ( Fang et al. 2013; Khanh et al. 2013).

\section{RICE MOMILACTONE INVOLVEMENT IN ALLELOPATHY EFFECT}

Most allelochemicals are classified as secondary metabolites, which are not required in primary metabolic processes (growth, development, and reproduction) of the allelopathic organisms (Ghahari and Miransari 2009; Belel and Rahimatu 2012). Many secondary compounds such as phenolic acids, hydroxamic acids, fatty acids, terpenes, and indoles were identified both in rice root exudates and rice residues as potential allelochemicals (Kato-Noguchi et al. 2010; Kato-Noguchi 2011; Kato-Noguchi 2012). However, although many secondary compounds have been reported as potential allelochemicals, only compounds that are released from the plants into environment and can inhibit the growth of neighboring plants that are considered as allelochemicals (Kato-Noguchi 2008; Kato-Noguchi et al. 2010 ).

Phenolic acid such as p-coumaric acid, $p$ hydroxybenzoic acid, ferulic acid and vanillic acid are found in aqueous extracts of rice straws, roots and residues and are often mentioned as the most important among potential allelochemicals (Kato-Noguchi 2004; Hui-Li et al. 2010; Siddique and Ismail 2013). However, their growth inhibition was relatively weak (Kato-Noguchi and Ino 2005a).

To investigate which secondary compounds possess allelopathic property in rice plants, eight Japonica type cultivars from Kinuhikari, Hinohikari, Nipponbare, Sasanishiki, Yukihikari, Norin 8, Kamenoo, and Koshihikari as donor plants were investigated on three sensitive plants to allelochemicals i.e., alfalfa (Medicago sativa L), cress (Lepidium sativum L.) and lettuce (Lactuca sativa $L$.) as receiver plants/ test plants. In this experiment, the effects of resource competition between donor and test plants such as water, nutrients and light were eliminated. Sterilized sixth day-rice seedlings were put on filter paper in Petri dish, moistened with phosphate buffer. Each of the three-day old test plants seedlings as described above, were then grown together with rice seedlings in Petri dish at $25^{\circ} \mathrm{C}$ and $12 \mathrm{~h}$ - photoperiod. The control experiment was conducted by growing each test plant without rice seedlings. All experiments were replicated seven times in complete randomized block designs. Three days after incubation, the lengths of roots and shoots and fresh biomass of the three test plants were measured. The results showed that all eight rice cultivars could inhibit the growth of the roots, shoots, and fresh mass of three test plants with different inhibition indexes, where the greatest inhibition index was reported from Koshihikari cultivar with the percentage of inhibition indexes on alfalfa, cress and lettuce as 60.6, 63.2 and 71.9, respectively (Kato-Noguchi and Ino 2001; Kato-Noguchi 2004; Kato-Noguchi and Peters 2013) (Table 1; Figure 2).

To find an allelochemical in rice root exudates that possess the greatest allelopathic potential, rice seedlings of Koshihikari cultivar were hydroponically grown for 14 days. The culture solution was then purified by chromatographic fractionations and finally, the putative compound with the inhibitory effect was isolated and the chemical structure of the putative inhibitor was determined by spectral data as momilactone B (3,20-epoxy-3 $\alpha$ hydroxy-synpimara-7,15-dien-19,6 $\beta$-olide, C20H26O4) (Kato-Noguchi 2004; Kato-Noguchi and Ino 2005b).

Table 1. Inhibition index of rice seedlings on alfalfa, cress, and lettuce seedlings (Kato-Noguchi and Ino 2001).

\begin{tabular}{lccc}
\hline \multicolumn{1}{c}{ Rice cultivars } & \multicolumn{3}{c}{ Inhibition index (\%)* } \\
& Alfalfa & Cress & Lettuce \\
\hline Norin 8 & 43.9 & 53.7 & 51.4 \\
Kamenoo & 22.3 & 46.6 & 53.2 \\
Nipponbare & 16.3 & 31.4 & 30.5 \\
Sasanishiki & 29.6 & 48.2 & 51.5 \\
Kinuhikari & 22.6 & 49.2 & 43.9 \\
Koshihikari & 60.6 & 63.2 & 71.9 \\
Hinohikari & 7.4 & 33.5 & 51.1 \\
Yukihikari & 27.1 & 30.4 & 39.9 \\
\hline
\end{tabular}

Note: $*$ The inhibition indexes were calculated on average of inhibition rate of root length, shoot length and fresh mass. Inhibition rate of root length, shoot length and fresh mass was scored so that those of control plants were $100 \%$.
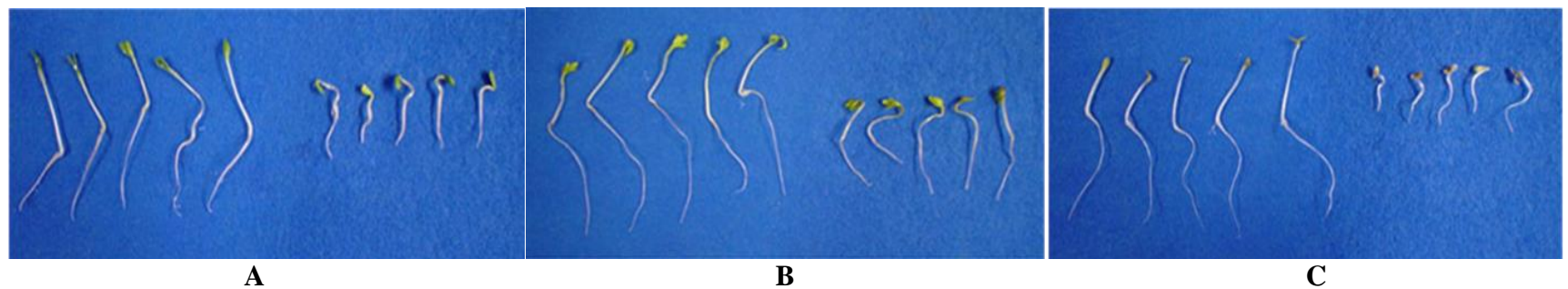

Figure 2. The growth of hypocotyls and roots of test plants i.e. (A) alfalfa; (B) cress and (C) lettuce when grown with and without rice seedlings cv. Koshihikari. The growth of test plants without rice seedlings/control (left); the growth of test plants with the presence of rice seedings/incubated with rice (right) (Kato-Noguchi 2004; Kato-Noguchi and Peters 2013). 
Table 2. $\mathrm{I}_{50}$ values of momilactone $\mathrm{A}$ and $\mathrm{B}$ on root and shoot growth of four weeds species (Kato-Noguchi and Ota 2013).

\begin{tabular}{lcccc}
\hline \multicolumn{1}{c}{ Cultivars } & \multicolumn{2}{c}{ Momilactone A } & \multicolumn{2}{c}{ Momilactone B } \\
& Root & Shoot & Root & Shoot \\
\hline Timothy & $76.5 \pm 6.3$ & $157 \pm 12$ & $5.6 \pm 0.4$ & $7.9 \pm 0.8$ \\
Barnyardgrass & $91.2 \pm 7.2$ & $145 \pm 11$ & $6.7 \pm 0.4$ & $6.3 \pm 0.4$ \\
Jungle rice & $66.7 \pm 5.4$ & $238 \pm 21$ & $7.2 \pm 0.5$ & $11.6 \pm 0.8$ \\
Crabgrass & $98.5 \pm 7.3$ & $275 \pm 19$ & $9.5 \pm 0.6$ & $12.4 \pm 1.1$ \\
\hline
\end{tabular}

In addition, another potential allelochemicals that were found in rice exudates of Koshihikari cultivar were identified as momilactone A. However, the ability of momilactone A to suppress the growth of neighboring plants is weaker compared to momilactone B (KatoNoguchi and Ino 2005a).

\section{RICE MOMILACTONES POTENTIAL FOR WEEDS SUPPRESSION}

To study the effectiveness of momilactone A and B against weed species, an experiment using four weeds species had been conducted by Kato-Noguchi and Ota (2013). Four weeds species, i.e., timothy (Phleum pratense L.), barnyardgrass (Echinochloa crus-galli (L) Beauv), jungle rice (Echinochloa colona L. Link) and crabgrass (Digitaria sanguinalis L.) were subjected to bioassay as test plants. Momilactone A and B were isolated from husks of rice cv. Koshihikari and dissolved in methanol and added to two sheets of filter paper in a Petri dish and allow to evaporate. The filter paper in Petri dish was moistened with $3 \mathrm{ml}$ of $1 \mathrm{mM}$ MES buffer. The final concentrations of momilactone A and B were 0.01, 0.03, 0.1, 0.3, 1,3, 10, 30, 100, 300, 1000, 3000 and $10000 \mu \mathrm{M}$. Sterilized ten germinated of each test plant seedlings were put on filter paper in Petri dish containing momilactones solution with different concentrations as above. The length of shoots and roots of test plants seedlings were measured after $48 \mathrm{~h}$ of incubation in the darkness at $25^{\circ} \mathrm{C}$. For the control experiment, sterilized ten germinated seeds of each test plant were placed on filter paper in Petri dish containing MES buffer without momilactones filtrate. Percentage of inhibition was calculated following the formula: [ (control plant length-plant length incubated with momilactone A or B )/control plant length ] x 100. The results showed that momilactone A and B can inhibit the growth of shoots and roots of all test plants. The concentrations of momilactone $A$ and $B$ required for $50 \%$ growth inhibition $\left(I_{50}\right)$ for shoots and roots of all test plants are presented in Table 2.

Table 2 showed that the $\mathrm{I}_{50}$ values of momilactone A on four weeds species were 66.7-98.5 $\mu \mathrm{M}$ and 145-275 $\mu \mathrm{M}$ for roots and shoots, respectively, meanwhile, the $\mathrm{I}_{50}$ values of momilactone B were 5.6-9.5 $\mu \mathrm{M}$ and 6.3-12.4 $\mu \mathrm{M}$ for roots and shoots, respectively. By comparing the $\mathrm{I}_{50}$ values of momilactone A and B on roots and shoots of four weeds cultivars, it showed that inhibitory activity of momilactone $\mathrm{B}$ on the roots of timothy, barnyardgrass, jungle rice and crabgrass were 13.7, 13.6, 9.26, and 10.4-fold higher than that of momilactone A. The inhibitory activity of momilactone B on the shoots of timothy, barnyardgrass, jungle rice and crabgrass were 19.9, 23.0, 20.5, and 22.2fold higher than that of momilactone A. Therefore, it could be suggested that momilactone B plays a more important role in weeds growth inhibition than momilactone A (KatoNoguchi and Ota 2013; Kato-Noguchi and Ino, 2005b).

In addition, an experiment using lettuce and Chinese cabbage has proven that the concentration of momilactone B at $10 \mu \mathrm{M}$ drastically could inhibit the growth of hypocotyls of lettuce and Chinese cabbage seedlings. Meanwhile, the application of momilactone A at $100 \mu \mathrm{M}$ exhibited only slightly inhibited both of test plants (Toyomasu et al. 2008). This data explained that momilactone B can suppress the growth of test plants with a concentration at $10^{-1}$ of momilactone A. In other words, momilactone $\mathrm{B}$ only requires low concentration to produce a high inhibition ability against surrounding plants (Trezzi et al. 2016). An extensive study on momilactone A reported that the function of momilactone $\mathrm{A}$ is more as a defense mechanism against fungal pathogen, which is termed as phytoalexin (Kato-Noguchi and Peters 2013; Atawong et al. 2002). Thus, momilactones have dual functions i.e., 1) as germination and seedling growth inhibitor (allelochemicals) and 2) as antimicrobial natural products (phytoalexins) (Wang et al. 2011; Toyomasu et al. 2008).

\section{RICE MOMILACTONES POTENTIALLY CAN INHIBIT THE GROWTH OF BARNYARDGRASS}

Most allelopathy studies were focused on one of the most noxious weeds in rice fields i.e., barnyardgrass (Khan et al. 2013; Kato-Noguchi and Peters 2013; Ma et al. 2014). To understand the correlation between allelopathic activity and momilactones secretion of eight rice cultivars, bioassay on barnyardgrass, using a method called donorreceiver bioassay, was conducted by Kato Noguchi (2010a). In this research, the interfering effects such as nutrients, light and $\mathrm{pH}$ were eliminated during the period of bioassay, thus the inhibitor effect of rice toward barnyardgrass was solely due to an allelopathy effect.

Sterilized seeds of eight rice cultivars i.e., Kinuhikari, Hinohikari, Nipponbare, Sasanishiki, Yukihikari, Norin 8, Kamenoo, and Koshihikari were germinated on a moist filter paper in Petri dish and incubated in growth chamber at $25^{\circ} \mathrm{C}$ and $12 \mathrm{~h}$ photoperiod. Four days after incubation, seedlings of each of the eight rice cultivars with uniform roots and shoots length were transferred into Petri dishes containing two sheets of filter paper moistened with MES buffer and allowed to grow for another three days. In the meantime, sterilized seeds of barnyardgrass were grown on a moist filter paper in Petri dish at $25^{\circ} \mathrm{C}$ in a darkness condition for three days. Further, barnyardgrass seedlings with uniform roots and shoots length were then moved into Petri dish that already contained 7-day-old rice seedlings and were incubated at $25^{\circ} \mathrm{C}$ and $12 \mathrm{~h}$ photoperiod. To maintain moisture, MES buffer was added into Petri dish at $12 \mathrm{~h}$ interval. The control experiment was conducted with 
the same protocol as above, but the weeds seedlings were grown without rice seedlings.

Three days after incubation, the length of roots and shoots of barnyardgrass were measured. Percentage of inhibition was calculated following formula: [(control plant length-plant length incubated with rice)/control plant length ] x 100. The liquid growth medium and filter paper in Petri dish were collected at the end of bioassays for further assay to determine momilactone $\mathrm{A}$ and $\mathrm{B}$ concentrations. The results showed that all rice cultivars inhibited the roots and shoot growth of barnyardgrass seedlings with different percentages of inhibition. The highest inhibition activity on the growth of barnyardgrass seedlings came from Koshihikari cultivar as well as the highest concentrations of momilactone $\mathrm{A}$ and $\mathrm{B}$ in their medium. Meanwhile, the lowest concentration of momilactones and the lowest activity of inhibition were found in Kinuhikari cultivar. Momilactone A and B in the medium of Koshihikari cultivar were 6.9-and 5.8- fold higher than Kinuhikari cultivar. The inhibition of roots and shoots growth of barnyardgrass seedlings by Koshihikari were 3.9- and 3.2-fold greater than Kinuhikari cultivar. Thus, Koshihikari cultivar released the highest concentration of momilactones and possess the highest inhibition on the growth of barnyardgrass seedlings (Table 3 and Table 4). Therefore, it could be suggested that there was correlation between the secretion level of momilactones and allelopathic activity. Increasing production of momilactones, increasing allelopathic activity. In addition, the secretion level of momilactones might be cultivar-dependent (Kato-Noguchi et al. 2010a).

\section{RICE MOMILACTONE B PLAY AN IMPORTANT ROLE IN INHIBITING THE GROWTH OF BARNYARDGRASS AND THEIR SECRETION WAS INDUCED BY THE PRESENCE OF WEEDS}

Rice momilactone $\mathrm{B}$ is reported to play a more important role in weeds growth inhibition than momilactone A. To study the presence effect of barnyardgrass on the concentration of secreted momilactone $\mathrm{B}$ from rice seedlings and its inhibitor activity as well, bioassay, where rice seedlings were incubated with (mixed-incubation) and without (mono-incubation) barnyardgrass seedlings, had been conducted by Kato Noguchi (2011b). Fifty sterilized seeds of rice cv. Koshihikari and 50 barnyardgrass seeds were grown separately on moist filter paper in a growth chamber at $25^{\circ} \mathrm{C}$ and $12 \mathrm{~h}$ photoperiod for 10 days. Ten-day-old uniform rice and barnyardgrass seedlings were then transferred onto a holed plate of polystyrene foam that was floated on Hoagland medium with $\mathrm{pH} 6.0$ in plastic container at $25^{\circ} \mathrm{C}$ and $12 \mathrm{~h}$ photoperiod. After 10 days of incubation, rice seedlings were harvested for barnyardgrass bioassay and momilactone $\mathrm{B}$ was determined.
Table 3. The inhibition of shoots and the roots growth of barnyardgrass seedlings when grown together with eight rice cultivars seedlings. Shoots and roots length of control plants were $19.7 \pm 0.9$ and $23.5 \pm 1.8 \mathrm{~mm}$, respectively. There were three replications per cultivar and the experiment was repeated seven times with three Petri dishes for each experiment. Different letters indicate significant differences $(\mathrm{P}<0.05)$ for each column according to Tukey's test (Kato-Noguchi et al. 2010a).

\begin{tabular}{|c|c|c|}
\hline \multirow[t]{2}{*}{ Rice cultivars } & \multicolumn{2}{|c|}{$\begin{array}{c}\text { Growth inhibition of } E \text {. crus-gall } \\
(\%)\end{array}$} \\
\hline & Shoot & Root \\
\hline Kinuhikari & $17.1 \mathrm{a}$ & $15.6 \mathrm{a}$ \\
\hline Hinohikari & $18.5 \mathrm{a}$ & $18.5 \mathrm{a}$ \\
\hline Nipponbare & $28.8 b$ & $25.5 b$ \\
\hline Sasanishiki & $38.8 \mathrm{c}$ & $29.5 b$ \\
\hline Yukihikari & $45.6 \mathrm{~d}$ & $38.2 \mathrm{c}$ \\
\hline Norin 8 & $48.8 \mathrm{~d}$ & 47.1d \\
\hline Катепоо & $51.8 \mathrm{de}$ & 54.8de \\
\hline Koshihikari & $54.5 \mathrm{e}$ & $60.3 \mathrm{f}$ \\
\hline
\end{tabular}

Table 4. Concentration of momilactone $\mathrm{A}$ and $\mathrm{B}$ in the culture medium of the donor-receiver bioassay as determined by LC/MS/MS analysis. Means from seven independent experiments with three replicates per cultivar. Different letters indicate significant differences $(\mathrm{P}<0.05)$ for each column according to Tukey's test (Kato-Noguchi et al. 2010a).

\begin{tabular}{lcc}
\hline Rice cultivars & $\begin{array}{c}\text { Concentration }(\boldsymbol{\mu m o l} / \mathbf{L}) \\
\text { Momilactone B }\end{array}$ \\
\hline Kinuhikari & $0.21 \mathrm{a}$ & $0.66 \mathrm{a}$ \\
Hinohikari & $0.27 \mathrm{~b}$ & $0.71 \mathrm{a}$ \\
Nipponbare & $0.29 \mathrm{~b}$ & $1.12 \mathrm{c}$ \\
Sasanishiki & $0.34 \mathrm{bc}$ & $1.41 \mathrm{c}$ \\
Yukihikari & $0.40 \mathrm{c}$ & $2.14 \mathrm{~cd}$ \\
Norin 8 & $1.03 \mathrm{~d}$ & $2.73 \mathrm{~d}$ \\
Kamenoo & $1.17 \mathrm{~d}$ & $3.23 \mathrm{df}$ \\
Koshihikari & $1.45 \mathrm{f}$ & $3.84 \mathrm{f}$ \\
\hline
\end{tabular}

Barnyardgrass bioassay was conducted by growing five-day-old uniform barnyardgrass in Petri dishes containing rice extracts, which is homogenized from $10 \mathrm{~g}$ fresh weight of rice seedlings. The control experiment did not contain rice extracts. The length of roots and shoots of barnyardgrass were measured $48 \mathrm{~h}$ after incubation in the darkness at $25^{\circ} \mathrm{C}$. Inhibitor activity (\%) was calculated by the formula: [ (control plant length-plant length treated with rice extract) /control plant length ] $\mathrm{x}$ 100. To determine momilactone $\mathrm{B}, 10 \mathrm{~g}$ of fresh weight of rice seedlings were homogenized with aqueous methanol and homogenate was filtered through filter paper No.2. This procedure was repeated two times to have an aqueous residue and further loaded into a column of synthetic polystyrene adsorbent, purified and finally momilactone B was calculated following method described by KatoNoguchi et al. (2002).

Bioassay where rice seedlings were incubated without (mono-incubation) barnyardgrass seedlings was conducted in the container. Barnyardgrass root exudates resulted by growing barnyardgrass seedlings onto a holed plate of polystyrene foam for 10 days. Then, the medium in the 
container was collected and filtered and the filtrate was loaded onto a column of synthetic polystyrene adsorbent, eluted with methanol, evaporated, and dissolved with methanol again and added to filter paper in incubation container. In the next step, $1 \mathrm{~L}$ of Hoagland nutrient solution was poured into the incubation container with different final concentrations of barnyardgrass root exudates in the medium i.e., $0,10,30,100,200$ and 300 $\mathrm{mg} / \mathrm{L}$. With the uniform rice seedlings being transferred onto a holed plate of polystyrene foam and floated in the container containing different concentrations of barnyardgrass root exudates as explained above for 10 days. At 10 days after incubation, the rice seedlings were then harvested and used for barnyardgrass bioassay and momilactone B was also quantified. Barnyardgrass bioassay and determination of momilactone $B$ in rice seedlings were performed by the same methods as above.

The results from mixed- and mono-incubation showed that the extracts resulting from mono-incubated rice could inhibit the roots and shoots of barnyardgrass as $15 \%$ and $12 \%$, respectively. Meanwhile, the extracts from mixedincubated rice could inhibit $79 \%$ and $75 \%$ of roots and shoots growth of barnyardgrass, respectively. Thus, mixed-incubation induced 5.3-fold increase in roots inhibition and 6.3-fold increase in shoots inhibition compared with mono-incubated rice. In line with allelopathy activity, the concentration of momilactone B was also higher in mix-incubated rice at $18.6 \mathrm{~nm} / \mathrm{seedling}$ than in mono-incubated rice at $2.7 \mathrm{~nm} /$ seedling. This number showed that the concentration of momilactone $\mathrm{B}$ was 6.9-fold higher in mixed-incubated rice than in monoincubated rice. Thus, the concentration and inhibitor activity of momilactone $\mathrm{B}$ were higher with the presence of barnyardgrass seedlings (Kato-Noguchi. 2011; Trezzi et al. 2016) (Figure 3). This condition was presumably because rice can detect root exudates of barnyardgrass which is contain signaling molecules that can induce the increased production and secretion of momilactone $\mathrm{B}$ into the environment (Kato-Noguchi and Peters 2013; Zhang et al. 2018; Kato-Noguchi 2011b).

In rice plants, momilactone $B$ was released into the environment during their life cycle and the released level was increasing until flowering initiation and afterward was decreased (Kato-Noguchi 2008; Kato-Noguchi et al. 2013). The concentration level of momilactone $\mathrm{B}$ at day 80 (around flowering) was 58- fold higher than at day 30 (Figure 8) and the level of momilactone B in the shoots was 3.8-fold greater than in the roots (Kato-Noguchi et al. 2011a; Kato-Noguchi and Ino 2005b). In high allelopathic rice varieties, the concentration of momilactone B per day can reach 2-3 $\mu \mathrm{g}$ (Soltys et al. 2013).
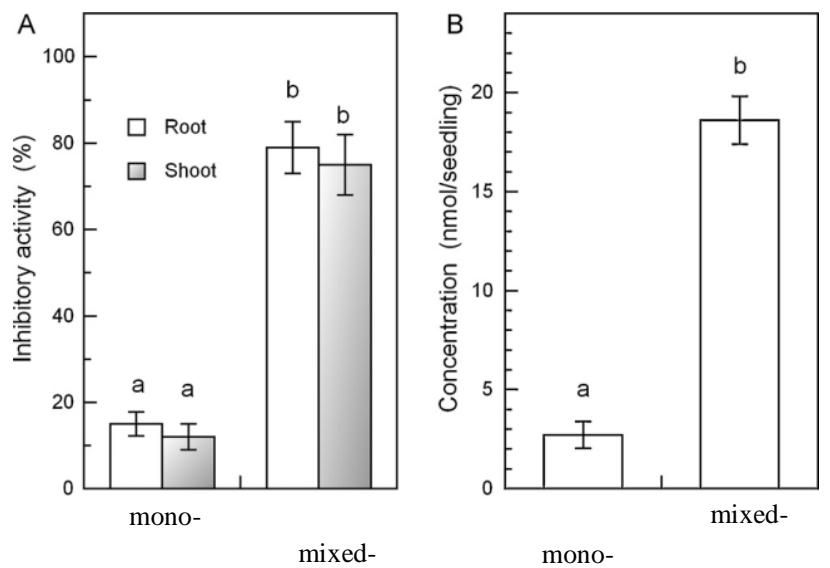

Figure 3. The inhibitor activity of allelopathic (A) and the concentration of momilactone B (B) in rice seedlings when grown together with (mixed-) and without (mono-) barnyardgrass seedlings (Kato-Noguchi 2011b).

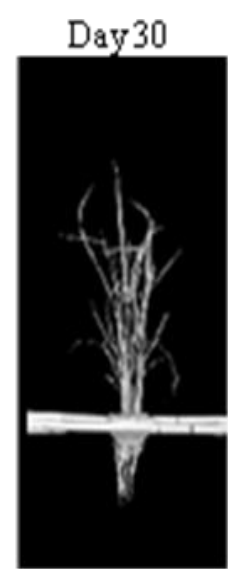

0.04

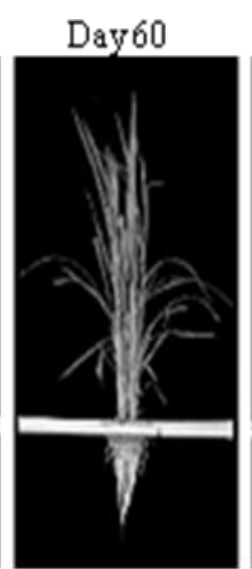

1.3

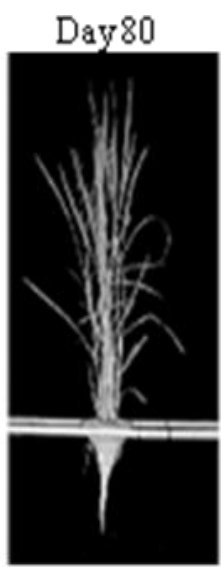

2.1

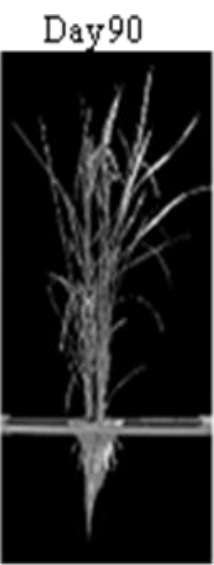

1.4

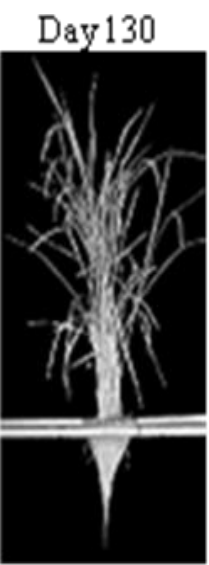

0.5

Level of momilactone B $(\mu \mathrm{g} /$ plant/day)

Figure 4. The secretion level of momilactone B from rice plants at different stages of growth (Kato-Noguchi and Ino, the regional institute online publishing) 


\section{Biosynthesis of momilactones and identified genes responsible for momilactones production}

The biosynthetic pathway of momilactones and their corresponding genes have been extensively investigated in rice (Okada et al. 2016). Genetic evidence is provided indicating that they form a gene cluster for momilactones production, located on chromosome 4 which includes copalyl diphosphate synthase 4 (OsCPS4), kaurene syntase-like 4 (OsKSL4), two cytochromes P450 (CYP) genes (CYP99A2 and CYP99A3), and a short chain alcohol dehydrogenase (SDR) (Kato-Noguchi and Peters. 2013; Miyamoto et al. 2014; Wang et al. 2011) (Figure 4). CYPs genes and a putative dehydrogenase gene (AK103462/ $O s M A S)$ are involved in the downstream steps of momilactones biosynthesis (Shimura et al. 2007; Xu et al. 2012; Miyamoto et al. 2014).

Momilactone biosynthesis is initiated by dual cyclization reactions (Figure 5). The initial cyclization of common diterpenoid precursor $(E, E, E)$-geranylgeranyl diphosphate (GGPP) to syn-copalyl diphosphate (syn-CPP) is catalyzed by copalyl diphosphate synthase OsCPS4 (Xu et al. 2012; Okada et al. 2016). Further cyclization of synCPP to $(9 \beta-\mathrm{H})$-pimarane-7,15-diene is catalyzed by $(9 \beta-\mathrm{H})-$ pimarane-7,15-diene synthase OsKSL4. Cytochromes $\mathrm{P} 450$ is involved in the downstream oxidation of the $(9 \beta-\mathrm{H})$ pimarane-7,15-diene. The involvements of one of cytochromes $\mathrm{P} 450$, CYP99A3 was found to catalyze consecutive oxidations of the $\mathrm{C}_{19}$ methyl group of the momilactone precursor, $(9 \beta-\mathrm{H})$-pimara-7,15-diene to form sequentially $(9 \beta-\mathrm{H})$-pimara $-7,15$-dien -19 -ol, $\quad(9 \beta-\mathrm{H})$ pimara-7,15 dien -19-al, and $(9 \beta-\mathrm{H})$-pimara-7,15 dien -19oic acid. Then, the (9 $\beta-\mathrm{H})$-pimara $-7,15$ - dien 19- oic acid give rise to $3 \beta$-hydroxy - (9 $\beta$-H)-pimara-7,15 dien- $19,6 \beta$ -olide and finally, the $3 \beta$-hydroxy - $(9 \beta-\mathrm{H})$-pimara-7,15 dien- 19,6 $\beta$-olide is converted to momilactone $\mathrm{A}$ by AK103462 (OsMAS) (Okada et al. 2009; Zhao et al. 2018). To produce momilactone $\mathrm{B}$, it is proposed to form from momilactone $\mathrm{A}$ through $\mathrm{C}_{20}$-hydroxylation and hemiketal ring closure (Wang et al. 2011; Zhao et al. 2018). In this biosynthetic pathway, CYP99A2 is one of cytochromes $\mathrm{P} 450$ is involved in a lesser extent compared with CYP99A3 (Zhao et al. 2018).

The involvements and the important role of OsCPS4 and OSKSLA in momilactones biosynthetic pathway and momilactones production, had been proven by selective removal of those genes using gene knock-out experiments (Xu et al. 2012). Reverse genetic approach by insertion genes knock-out of OsCPS4 and OsKSL4 in Zhonghua 11 and Hwayoung rice cultivars has been conducted (Xu et al. 2012). Bioassays to determine the effect of removing cps 4 or ksl4 on plant suppression were conducted by growing homozygous insertional mutant lines either harboring cps 4 or ksl4 together with lettuce (the sensitive plant species) or barnyardgrass (noxious weed) in Petri dishes without any supplied nutrients to avoid any confounding. The control experiment was conducted by growing barnyardgrass or lettuce together with wild-type rice seedlings. Parameters observed in this experiment were the length of roots and hypocotyls after 6 or 12 days after incubation for lettuce and barnyardgrass, respectively.

The results showed that homozygous insertional mutant lines harboring either cps 4 or ksl 4 exhibited the decreasing in allelopathy potential on both lettuce and barnyardgrass as shown in Figures 6 and 7. The length of roots and hypocotyls of lettuce and barnyardgrass were longer when they were grown together with mutant rice lines seedlings compared with their wild type of rice. In other words, the wild type has an allelopathy effect greater than mutant lines. It is suggested that in mutant rice lines, they lose their ability to suppress the growth of neighboring plants due to the loss of OsCPS4 or OsKSL4 gene expression which directly influences momilactones production (Xu et al. 2012; Kato-Noguchi and Peters 2013; Kato-Noguchi and Ota 2013). Thus, it is proved that momilactones have a direct role in allelopathy ability. However, phenotypically, those mutant lines exhibited normal growth through all stages of development ( $\mathrm{Xu}$ et al. 2012).

In addition, it was reported that the OsTGAPlis an elicitor-inducible rice basic leucine zipper (bZIP) transcription factor which plays an important role in momilactones biosynthesis and regulates the expression of all five genes in the cluster (Figure 4). Knock-out mutant line of OsTGAP1 showed no expression of OsCPS4, OsKSLA, CYP99A2, CYP99A3 and OSMAS and the absence of momilactones production. Therefore, OsTGAPlis proven as a key regulator for elicitor-inducible production of momilactones and to coordinate the transcription of all five genes essential for momilactones production (Okada 2009; Zhao et al. 2018).

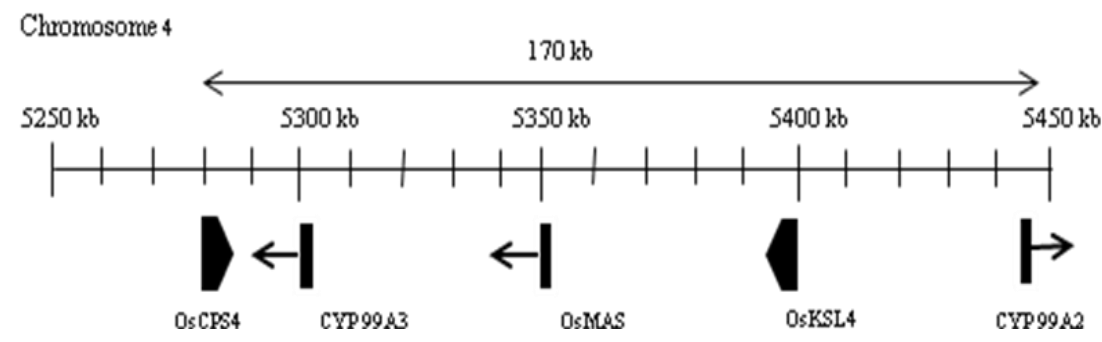

Figure 4. Rice momilactones biosynthetic gene cluster (Xu et al. 2012). 


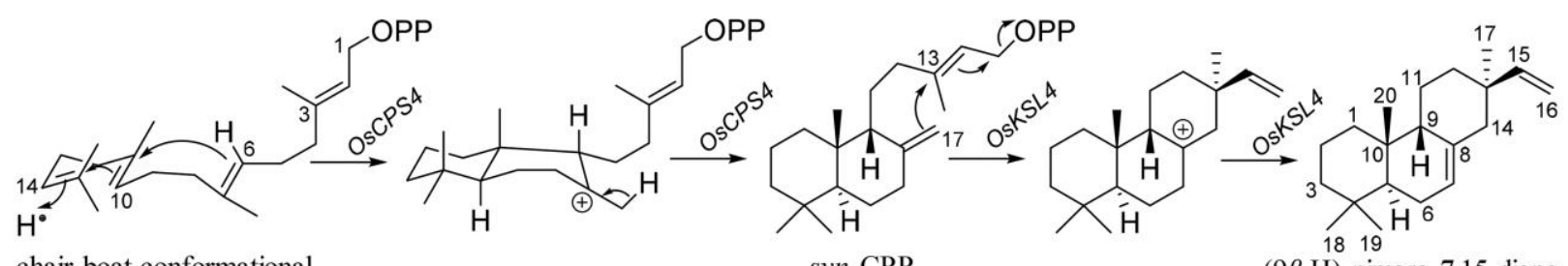

chair-boat conformational

syn-CPP

$(9 \beta$-H)-pimara-7,15-diene

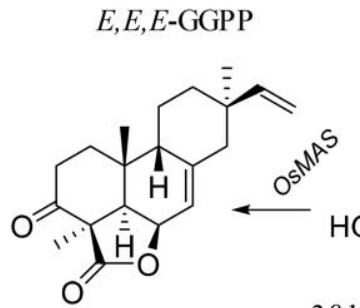<smiles>C=CC=CC</smiles>

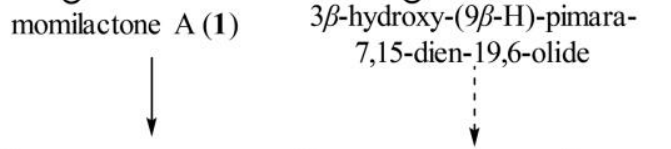

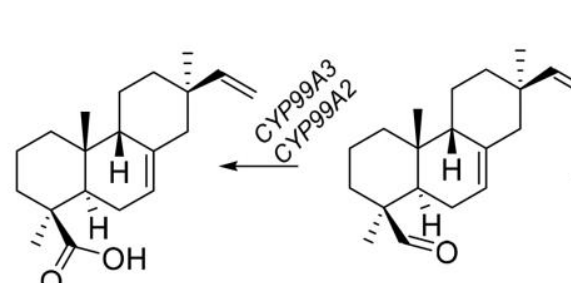

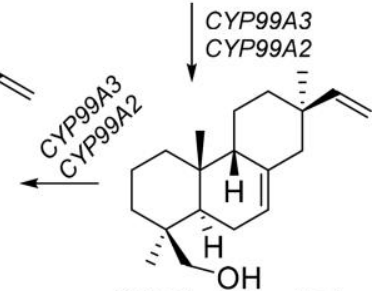<smiles>C/C=C\[C@]1(C)CC[C@@H]2C(=C[C@@H]3OC(=O)[C@@]4(C)C(=O)CC[C@@]324)C1</smiles>

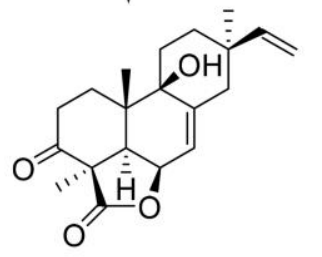

momilactone D (5)

(9 $\beta$-H)-pimara-7,15dien-19-oic acid

$(9 \beta-\mathrm{H})$-pimara-7,15dien-19-al<smiles>C=C[C@]1(C)CC[C@H]2C(=C[C@H](O)[C@@H]3[C@@H](C)C(=O)CC[C@]3(C)[C@H]2C)C1</smiles>

momilactone $\mathrm{C}(3)$

momilactone $\mathrm{E}(6)$

\section{$E, E, E$-GGPP: $E, E, E$-geranylgeranyl pyrophosphate syn-CPP: syn-copalyl diphosphate}

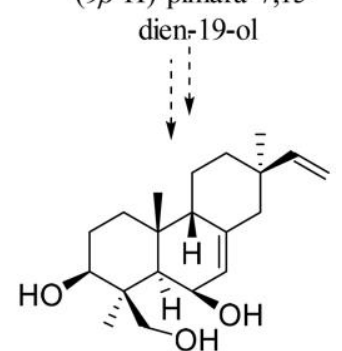

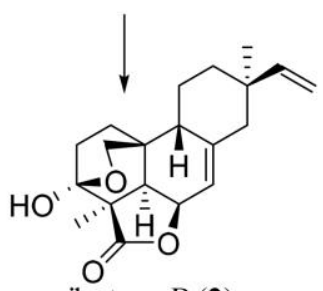

momilactone B (2)

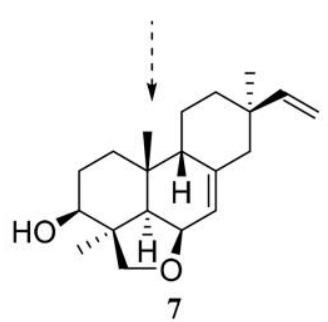

Figure 5. Biosynthesis pathway of momilactone A and B (Zhao et al. 2018).
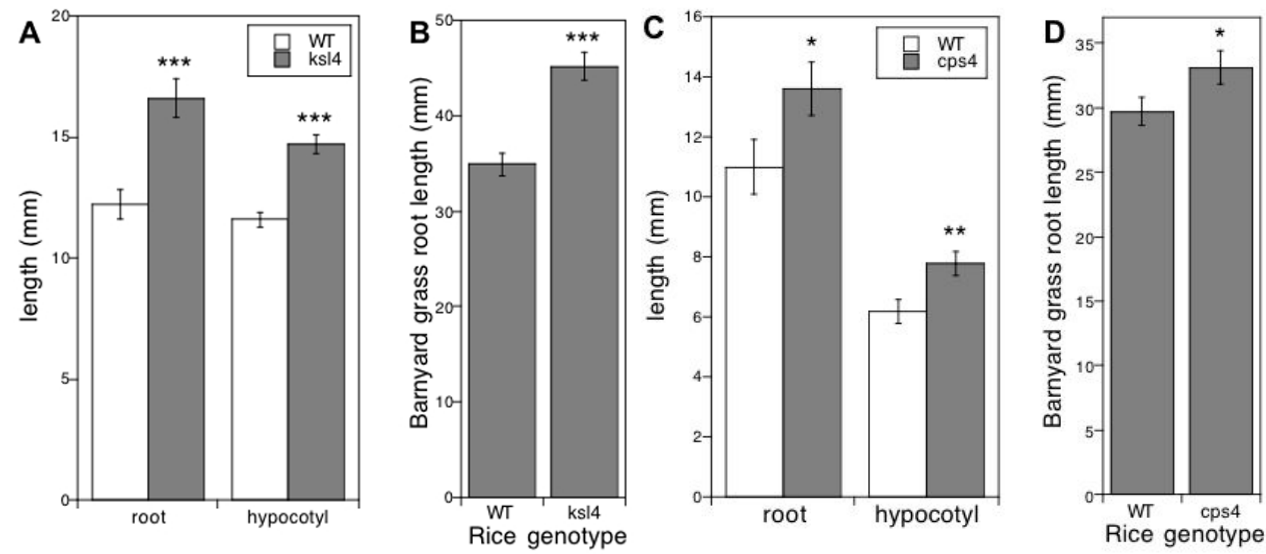

Figure 6. Effect of OsKSL4 and OsCPS4 knock-out mutants rice ( $k s l$ and $c p s 4$ ) on allelopathy potential against lettuce (A and C) and barnyardgrass (B and D). Comparison of the length of roots and hypocotyls seedlings of lettuce and barnyardgrass when they were grown together with mutant rice versus their wild type of rice seedlings (Xu et al. 2012). 


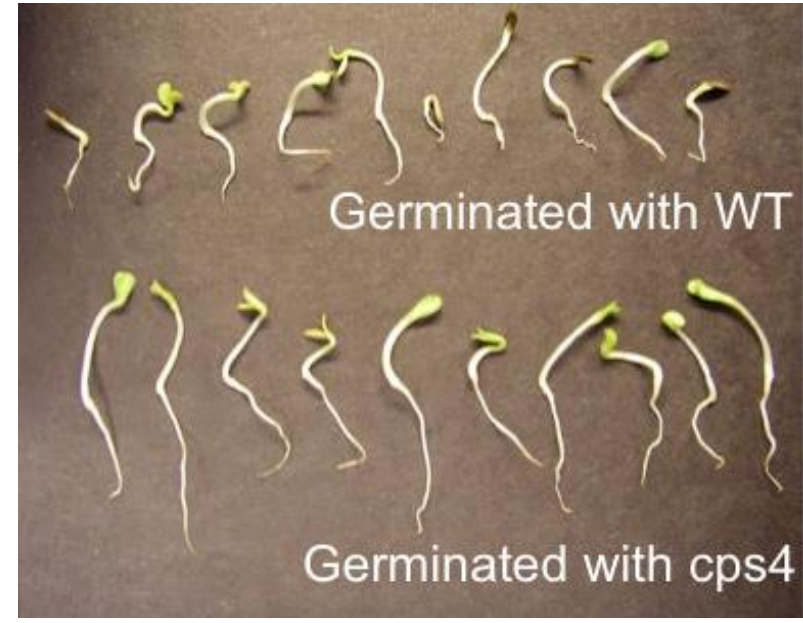

Figure 7. Comparison of allelopathy potential in mutant rice lines versus wild-type rice on germinated lettuce seedlings (Xu et al. 2012).

\section{Discussion}

One of the most important factors that play a role in the declining yield and the quality of rice are weeds. In paddy fields, cultivated rice and weeds always grow together for the same needs. Among weed species, barnyardgrass was reported as the most destructive weed and the most serious herbicide-resistant weed (Zhang et al. 2018). Farmers control weeds by using synthetic herbicides. However, the overuse and continuous use of synthetic herbicides can lead to the emergence of herbicide-resistant weeds and moreover give negative effects on the environment and human health. Therefore, an alternative method to control the weed problem is by minimizing the use of synthetic herbicides should be considered.

Rice has self-defense mechanisms by secreting phytotoxic compounds into the environment that can suppress the germination and growth of weeds nearby. This kind of self-defense is called allelopathy (Heidarzade et al. 2012; Zhang et al. 2018). Allelopathy is important to prevent rice plants from interfering with weeds. Allelopathy is defined as any direct or indirect harmful effects of one plant on another through the production of chemical compounds that releases into the environment called allelochemicals. There are many secondary compounds that are potential allelochemicals. Researchers are interested in studying which allelochemicals are the most responsible compounds for inhibiting weed growth. This article summarized published literature to determine the important compounds of rice allelochemicals that play an important role in suppressing weed growth. All experiments have been conducted in laboratories to eliminate other resources competitive interference. Therefore, the data obtained from the experiments solely reflects the allelopathic effect.

Although rice has the ability to suppress root growth of barnyardgrass, its abilities, however, vary among cultivars. Thus, the activity of allelopathy is cultivars-specific. From microscopic studies, rice cv. IR64 with potential allelopathic can inhibit the growth of secondary roots of barnyardgrass but not with non-allelopathic rice plant cv.
Aus 196 (Olofsdotter et al. 2002). A study explained that among allelochemicals, momilactone $\mathrm{A}$ and $\mathrm{B}$ are the most important compounds with allelopathic potential, although momilactone B plays a more important role in weeds growth inhibition than momilactone A (Kato-Noguchi and Ota 2013; Kato-Noguchi and Ino 2005a). Momilactone A function is reported more as defense mechanism against fungal pathogen called phytoalexin.

The genes involved in momilactones biosynthetic pathway and thus directly affecting momilactones production, form a gene cluster consisting of OsCPS4, OSKSL4, CYP99A2, CYP99A3 and OSMAS located on chromosome 4 and all these five genes are coordinately regulated by OsTGAP1. To prove the involvement of OsCPS4 and OsKSL4 genes in momilactones biosynthetic pathway and production, a reverse genetic approach by using gene knock-out of both genes has been conducted by $\mathrm{Xu}$ et al. (2012). The homozygous cps4 or ksl4 knock-out lines exhibited a significant loss in suppressing the growth of lettuce and barnyardgrass. This data is direct evidence that the loss of allelopathic ability in mutant lines to suppress the neighboring plants is due to the loss of OsCPS4 and OsKSL4 genes expression as well as momilactones production ( $\mathrm{Xu}$ et al. 2012). The same results were obtained in knock-out mutant line of tgapl which exhibited no expression of OsCPS4, OsKSL4, CYP99A2, CYP99A3 and OSMAS and no momilactones production. Thus, it could be concluded that momilactones is played an important role in allelopathy activity.

In the future, momilactones act as natural plant growth suppressants that are environmentally friendly, could be contributed as an alternative to the use of synthetic herbicides in weed management strategy. However, bioassays in greenhouse that imitate the situation in the field and continued with field studies to demonstrate the efficacy of momilactones still need to be carried out.

\section{REFERENCES}

Amb MK, Ahluwalia AS. 2016. Allelopathy: Potential role to achieve new milestones in rice cultivation. Rice Sci. 23 (4): 165-183

Asaduzzaman MD, Islam MM, Sultana S. 2010. Allelopathy and allelochemicals in rice weed management. Bangladesh Research Publications Journal 4 (1): 1-14

Atawong A, Hasegawa M, Kodama O. 2002. Biosynthesis of rice phytoalexins: Enzymatic conversion of $3 \beta$-hydroxy $-9 \beta$ pimara $-7,15$ dien-19,6 $\beta$-olide to mamilactone A. Biosci. Biotechnol. Biochem.66 (3): 566-570.

Bellel MDA, Rahimatu DB. 2012. Allelopathic Effect of Cyperus tuberosus Seed and Leaf Extract on Seedling Growth of Groundnuts (Arachis hypogaea). J. Agric. Soc. Sci. 8: 87-91.

Bhadoria PBS. 2011. Allelopathy: A natural way towards weed management. Amer J Exp Agric. 1 (1): 7-20.

Bravo HR, Copaja SV, Lamborot M. 2013. Phytotoxicity of phenolic acids from cereals. DOI: $10.5772 / 55942$

Colquhoun JB. 2006. Allelopathy in weeds and crops: Myths and facts. Proc. of the 2006 Wisconsin Fertilizer, Aglime \& Pest Management Conference 45: 318-320

de Bertoldi C, De Leo M, Braca A, Ercoli L. 2009. Bioassay-guided isolation of allelochemicals from Avena sativa L.: Allelopathic potential of flavone $C$-glycosides. Chemoecology 19: 169-176.

Dilday RH, Nastasi P, Smith, JR. RJ. 1989. Allelopathic observation in rice (Oryza sativa L.) to duck salad (Heteranthera limosa). Proc Arkansas Acad Sci 43: 21-22 
Fang C, Zhuang Y, Xu T, Li Y, Li Y, Lin W. 2013. Changes in rice allelopathy and rhizosphere microflora by inhibiting rice phenylalanine ammonia-lyase gene expression. J Chem Ecol. DOI 10.1007/s10886-013-0249-4

Farooq M, Bajwa AA, Cheema SA, Cheema ZA. 2013. Application of allelopathy in crop production. Intl J Agric Biol 15: 1367-1378.

Ferreira MI, Reinhardt CF. 2010. Field assessment of crop residues for allelopathic effects on both crops and weeds. Agron J 102 (6): 1593 1600 .

Gealy D, Moldenhauer K, Duke S. 2013. Root distribution and potential interactions between allelopathic rice, sprangletop (Leptochloa spp.), and barnyardgrass (Echinochloa cruss-galli) based on ${ }^{13} \mathrm{C}$ Isotope discrimination analysis. J Chem Ecol 39: 186-203.

Ghahari S, Miransari M. 2009. Allelopathic effects of rice cultivars on the growth parameters of different rice cultivars. Intl J Biol Chem 3 (2): 56-70.

He HB, Wang HB, Fang CX, Lin ZH, Yu ZM, Lin WX. 2012. Separation of allelopathy from resource competition using rice/barnyardgrass mixed-cultures. PloS One 7 (5): e37201.

Heidarzade A, Esmaeili M, Pirdashti H. 2012. Common allelochemicals in root exudates of barnyardgrass (Echinochloa crus-galli L.) and inhibitory potential against rice (Oryza sativa) cultivars. Intl Res J Appl Basic Sci 3 (1): 11-17

Hui Li Z, Wang Q, Ruan X, De Pan C, An Jiang D. 2010. Phenolics and plant allelopathy. Molecules 15: 8933-8952.

Jensen LB, Courtois B, Shen L, Li Z, Olofsdotter M, Mauleon RP. 2001. Locating genes controlling allelopathic effects against barnyardgrass in upland rice. Agron J 93: 21-26.

Kato-Noguchi H, Ino T. 2001. Assessment of allelopathic potential of root exudate of rice seedlings. Biologia Plantarum 44 (4): 635-638.

Kato-Noguchi H, Tanaka Y, Murakami T, Yamamura S, Fujihara S. 2002. Isolation and identification of an allelopathic substance from peel of Citrus junos. Phytochemistry 61: 849-853.

Kato-Noguchi H. 2004. Allelopathic substance in rice root exudates: Rediscovery of momilactone B as an allelochemical. J Plant Physiol 161: 271-276.

Kato-Noguchi H, Ino T. 2005a. Concentration and release level of momilactone B in the seedlings of eight rice cultivars. J Plant Physiol 162: 965-969.

Kato-Noguchi H, Ino T. 2005b. Possible involvement of momilactone B in rice allelopathy. J Plant Physiol 162: 718-721

Kato-Noguchi H, Ino T, Ota K . 2008. Secretion of momilactone A from rice roots to the rhizosphere. J Plant Physiol 165 (7): 691-696.

Kato-Noguchi H, Hasegawa M, Ino T, Ota K, Kujime H. 2010. Contribution of momilactone $\mathrm{A}$ and $\mathrm{B}$ to rice allelopathy. J Plant Physiol 176: 787-791.

Kato-Noguchi H. 2011a. Rice allelopathy and momilactone. 23 ${ }^{\text {rd }}$ AsianPacific Weed Science Society Conference. The Sebel Cairns, 26-29 September 2011. p: 246-252.

Kato-Noguchi H. 2011b. Barnyardgrass-induced rice allelopathy and momilactone B. J Plant Physiol 168: 1016-1020.

Kato-Noguchi H. 2012. Rice allelopathy and momilactone. Pak J Weed Sci Res 18: 289-296.

Kato-Noguchi H, Ota K. 2013. Biological activities of rice allelochemicals momilactone A and B. J Rice Res 1 (2): 1-5.

Kato-Noguchi H, Ota K, Kujime H, Ogawa M. 2013. Effects of momilactone on the protein expression in Arabidopsis germination. Weed Biol Manag 13: 19-23.

Kato-Noguchi H, Peters RJ. 2013. The role of momilactones in rice allelopathy. J Chem Ecol 39: 175-185.

Khanh TD, Linh LH, Linh TH, Quan NT, Cuong DM, Hien VTT. 2013 Integration of allelopathy to control weeds in rice. Chapter 4. http://dx.doi.org/10.5772/56035.

Khang DT, Anh LH, Ha PTT, Tuyen PT, Quan NV, Minh LT, Quan NT, Minh TN, Xuan TD, Khanh TD, Trung KH. 2016. Allelopathic activity of dehulled rice and its allelochemicals on weed germination. Intl Lett Nat Sci 58: 1-10.

Kong $\mathrm{CH}, \mathrm{Hu} \mathrm{F}$, Wang $\mathrm{P}, \mathrm{Wu} \mathrm{JL}$. 2008. Effect of allelopathic rice varieties combined with cultural management options on paddy field weeds. Pest Manag Sci. 64 (3): 276-282.

Ma Y, Zhang M, Li Y, Shui J, Zhou Y. 2014. Allelopathy of rice (Oryza sativa L.) root exudates and its relations with Orobanche cumana Wallr. and Orobanche minor Sm. germination. J Plant Interact 9 (1): 722-730.

Miyamoto K, Shimizu T, Okada K. 2014. Transcriptional regulation of the biosynthesis of phytoalexin: A lesson from specialized metabolites in rice. Plant Biotechnol 31:377-388.

Mohammadi GR. 2013. Alternative weed control methods. Chapter 6. http://dx.doi.org/10.5772/54164

Okada A, Okada K, Miyamoto K, Koga J, Shibuya N, Nojiri H, Yamane H. 2009. OsTGAP1, a bZIP transcription factor, coordinately regulates the inductive production of diterpenoid phytoalexins in rice. J Biol Chem 284 (39): 26510-26518.

Okada K, Kawaide H, Miyamoto K, Miyazaki S, Kainuma R, Kimura H, Fujiwara K, Natsume M, Nojiri H, Nakajima M, Yamane H, Hatano Y, Nozaki H, Hayashi K. 2016. HpDTC1 a stress-inducible bifunctional diterpene cyclase involved in momilactone biosynthesis, functions in chemical defense in the Moss Hypnum plumaeformae. Nature Sci Rep. DOI:10.1038/srep25316.

Olofsdotter M, Jensen LB, Courtois B. 2002. Improving crop competitive ability using allelopathy - An example from rice. Plant Breed 121: 19 .

Shimura K, Okada A, Okada K, Jikumaru Y, Ko KW, Toyomasu T, Sassa T, Hasegawa M, Kodama O, Shibuya N, Koga J, Nojiri H, Yamane H. 2007. Identification of a biosynthetic gene cluster in rice for momilactones. J Biol Chem 282 (47): 34013-34018.

Siddique AB, Ismail BS. 2013. Rice ecosystem, allelopathy, and environment- A Review. Agriculturists 11 (1): 112-121.

Soltys D, Krazuska U, Bogatek R, Gniazdowska A. 2013. Allelochemicals as bioherbicides -Present and Perspectives. Chapter 20. DOI: $10.5772 / 56185$

Tanveer A, Javaid MM, Khaliq A, Abbas RN, Azis A. 2012. Allelopathic effect of Echinochloa crus-galli on fields crops. Herbologia 13 (2): 918 .

Toyomasu T, Kagahara T, Okada K, Koga J, Hasegawa M, Mitsuhashi W, Sassa T, Yamane H. 2008. Diterpene phytoalexins are biosynthesized in and exuded from the roots of rice seedlings. Biosci Biotechnol Biochem 72 (2): 562-567.

Trezzi MM, Vidal RA, Junior AAB, Bittencourt HH, Filho APSS. 2016. Allelopathy: driving mechanisms governing its activity in agriculture. J Plant Interact 11 (1): 53-60.

Wang Q, Hillwig ML, Peters RJ. 2011. CYP99A3: Functional identification of a diterpene oxidase from the momilactone biosynthetic gene cluster in rice. Plant J 65 (1): 87-95.

Xu M, Galhano R, Wiemann P, Bueno E, Tiernan M, Wu W, Min Chung I, Gershenzon J, Tudzynski B, Sesma A, Peters RJ. 2012. Genetic evidence for natural product mediated plant-plant allelopathy in rice. New Phytol 193 (3): 570-575.

Yang X, Yu XY, Li YF. 2013. De novo assembly and characterization of the barnyardgrass (Echinochloa cruss-galli) transcriptome using next-generation pyrosequencing. PloS One 8 (7): e69168.

Zeinali A, Esmaeili M, Heidarzade A. 2013. Salicylic acid and abiotic stress influence allelochemicals and inhibitory potential of root exudates of two rice (Oryza sativa) cultivars against barnyardgrass (Echinochloa crus-galli L.). Intl J Farm Alli Sci. 2 (19): 779-784.

Zhang T, Fan B, Wang P. 2018. Barnyardgrass root recognition behaviour for rice allelopathy. www. mdpi.com/journal/agronomy. 8,39; doi:33910/agronomy 8040039

Zhao M, Cheng J, Guo B, Duan J, Tao Che C. 2018. Momilactone and related diterpenoids as potential agricultural chemicals. J Agric Food Chem 66: 7859-7872. 